\title{
RNA-sequencing analysis of lung primary fibroblast response to eosinophil-degranulation products predicts downstream effects on inflammation, tissue remodeling and lipid metabolism
}

\author{
Stephane Esnault ${ }^{1 *}$ D, Ksenija Bernau', Elizabeth E. Torr ${ }^{1}$, Yury A. Bochkov², Nizar N. Jarjour ${ }^{1}$ and Nathan Sandbo ${ }^{1}$
}

\begin{abstract}
Background: The association of eosinophils with inflammation and tissue remodeling is at least partially due to their release of toxic granule proteins and other mediators, including cytokines. Tissue remodeling and consequent functional defects are affected by activity of connective tissue fibroblasts. Exaggerated fibroblast activation, accumulation and change of phenotype may lead to fibrosis and loss of tissue function. So far, little information has been reported on how eosinophils affect inflammation and tissue remodeling via the activation of fibroblasts. We have recently shown that eosinophil activation with IL-3 led to a robust eosinophil degranulation on immunoglobin-G (lgG) coated plates. Thus, in the present study, we analyze the effects of IL-3-activated eosinophil degranulation products on primary human lung fibroblasts (HLF) using whole transcriptome sequencing.

Methods: Conditioned media was obtained from eosinophils that were pre-activated with IL-3 or IL-5 and subsequently cultured for $6 \mathrm{~h}$ on IgG to induce degranulation. This conditioned media was added on human lung fibroblasts (HLF) for $24 \mathrm{~h}$ and the cell lysates were then subjected to whole transcriptome sequencing to identify global changes in gene expression. Differentially expressed genes were analyzed using the Ingenuity Pathway Analysis (IPA), and validated by qPCR.

Results: In HLF, the expression level of 300 genes was changed by conditioned media from IL-3-activated eosinophils compared to control fibroblast cultures. Among these 300 genes, the expression level of 35 genes coding for known proteins was upregulated by IL-3- versus IL-5-pre-activated eosinophils. Of the 35 upregulated genes, IPA identified C3, CH25H, CXCL1, CXCL8, CYP1A1, ICAM1, IL6 and UCN2 as having downstream functions on inflammation, tissue remodeling and lipid synthesis. This analysis combined with previous RNA sequencing analyses of eosinophils suggest IL-1B, OSM and TNFSF12 as potential upstream regulators of fibroblasts.

(Continued on next page)
\end{abstract}

\footnotetext{
* Correspondence: sesnault@medicine.wisc.edu

'Department of Medicine, Division of Allergy, Pulmonary and Critical Care

Medicine, The University of Wisconsin-Madison School of Medicine and

Public Health, K4/928 Clinical Science Center MC 9988, 600 Highland Avenue,

Madison, WI 53792, USA

Full list of author information is available at the end of the article
} 
(Continued from previous page)

Conclusions: This study has identified several novel pro-inflammatory and pro-remodeling mediators produced by fibroblasts in response to activated eosinophils. These findings may have significant implications on the role of eosinophil/fibroblast interactions in eosinophilic disorders.

Keywords: Fibroblast, Eosinophil, I-3, IgG, Degranulation, Lung, RNA-sequencing, Inflammation, Tissue remodeling, Lipid metabolism

\section{Background}

Allergic inflammation is characterized by a type- 2 immune response. Mast cells and eosinophils are critical for the development of early- and late-phase type-2 immune response, respectively. Eosinophilia has been associated with chronic asthma symptoms and severity [1-4]. Evidence suggests that eosinophils contribute to asthma pathogenesis via the release of cytotoxic granule proteins and other mediators, including cytokines and lipids $[5,6]$. The release of these mediators from eosinophils leads to tissue damage and recruitment/activation of other cell types, including fibroblasts.

Asthma is marked by airway inflammation and remodeling. The structural changes of airway remodeling result in airflow limitation and are associated with increased asthma severity [7]. Airway remodeling includes epithelial changes, angiogenesis, and increased smooth muscle mass, and activation of fibroblasts to differentiate into pro-inflammatory-producing fibroblasts and extracellular matrix (ECM)-producing myofibroblasts [8].

Eosinophils are an important source of growth factors and cytokines that can influence fibroblast function and airway remodeling. Transforming growth factor- $\beta$ (TGF$ß)$ and interleukin-1 (IL-1) are two cytokines that have been implicated in airway remodeling, and they are known to be derived from eosinophils [9-15]. TGF- $\beta$ can activate fibroblasts to differentiate into myofibroblasts and to produce pro-fibrotic proteins [10, 16, 17]. IL-1 also can induce airway remodeling [18], but interestingly IL-1 and TGF- $\beta$ may have opposing effects on the differentiation of fibroblasts, as TGF- $\beta$-induced fibroblast differentiation can be attenuated by IL-1, particularly in lung fibroblasts [19-21]. Moreover, TGF- $\beta$ and IL-1, associated with the eosinophil granule major basic protein (MBP), can induce expression of the profibrotic and inflammatory IL-6 family genes (IL-6, IL-11, and leukemia inhibitory factor) [22]. Human blood eosinophils co-cultured with skin fibroblasts leads to secretion of IL-6, CXCL1, and CCL2 from fibroblasts independently of cell contact, indicating that soluble mediators are responsible for activation of these genes in fibroblasts [23, 24]. Therefore, while the role of eosinophils on the fibroblast biology has been previously studied and reported, the expression level of only few genes has been examined.
Eosinophil-driven pathology involves the release of toxic proteins and mediators involved in inflammation and remodeling, via degranulation or piecemeal release. Because high amounts of immunoglobulin G (IgG) are present in airways $[25,26]$, eosinophil degranulation on IgG has been used as a physiologically relevant model to analyze the mechanisms of eosinophil degranulation $[27,28]$. We have recently reported that IL-3-pre-activated eosinophil strongly degranulated on heat aggregated human IgG (HA-IgG), releasing $\sim 25 \%$ of their total cellular eosinophil-derived neurotoxin (EDN) in $6 \mathrm{~h} \mathrm{[29].} \mathrm{In} \mathrm{the} \mathrm{present} \mathrm{study,} \mathrm{we} \mathrm{have} \mathrm{used} \mathrm{this} \mathrm{eosino-}$ phil degranulation model [29] to examine the function of the endogenic eosinophil compounds on primary human lung fibroblasts (HLF). To understand the global effects of eosinophil mediators on fibroblasts, we performed whole-transcriptome RNA sequencing (RNA-seq) analysis of gene expression in cultured HLF. We hypothesized that fibroblast response to eosinophildegranulation products would lead to potential downstream effects on tissue inflammation and remodeling.

\section{Methods}

\section{Subjects, cell preparations and cultures}

Eosinophil isolation was performed under a study protocol approved by the University of Wisconsin-Madison Health Sciences Institutional Review Board. Informed written consent was obtained from subjects prior to participation. Peripheral blood eosinophils were obtained from allergic subjects with $(n=2)$ and without mild asthma $(n=1)$. Subjects with prescriptions for low doses of inhaled corticosteroids did not use their corticosteroids the day of the blood draw.

Eosinophils were purified by negative selection as previously described [29] from three female donors with $0.12,0.2$ and $0.47 \times 10^{6}$ eosinophils per $\mathrm{ml}$ of whole blood. Briefly, $200 \mathrm{ml}$ of heparinized blood was diluted 1:1 in HBSS and was overlaid above Percoll $(1.090 \mathrm{~g} / \mathrm{ml})$. After centrifugation at $700 \mathrm{xg}$ for $20 \mathrm{~min}$, at room temperature, the mononuclear cells were removed from the plasma/Percoll interface and erythrocytes were eliminated from the cell pellet by hypotonic lysis. The remaining pellet was resuspended in $2 \%$ new calf serum in HBSS. Cells were then incubated with anti-CD16, anti-CD3, anti-CD14 and anti-Glycophorin-A beads 
from Miltenyi (San Diego, CA), and run through an AutoMACS (Miltenyi). Eosinophil preparations with purity $>99 \%$ and viability $~ 98 \%$ were used the same day, $\sim 5 \mathrm{~h}$ after the blood draw.

Human lung fibroblasts (HLF) were isolated as described previously $[30,31]$ using de-identified tissue samples from thoracic surgical resection specimens. These samples were collected and characterized in collaboration with the biobanking services run by the Carbone Cancer Center Translational Science BioCore at the University of Wisconsin-Madison, under Institutional Review Board approval. To obtain non-fibrotic fibroblasts, we utilized adjacent (uninvolved) lung from lobectomy or biopsy specimens from patients undergoing lung resection for pulmonary nodules and who did not have any identifiable lung disease by history or histologic assessment. All specimens used for fibroblast isolation were examined by a pathologist to ensure that no underlying lung disease (emphysema, idiopathic lung diseases, etc.) was present on histology. Briefly, to isolate fibroblasts, tissue specimens were placed in DMEM with 100 units $/ \mathrm{ml}$ streptomycin, $250 \mathrm{ng} / \mathrm{ml}$ amphotericin $\mathrm{B}, 100$ units $/ \mathrm{ml}$ penicillin, and $10 \mu \mathrm{g} / \mathrm{ml}$ ciprofloxacin. Alveolated lung tissue was minced and plated onto $10-\mathrm{cm}$ plates in growth medium containing DMEM supplemented with 10\% FBS, $2 \mathrm{mM}$ L-glutamine, and antibiotics, as above. Expanded populations of fibroblasts were subsequently subcultured after 4-5 days, resulting in the development of a homogenous fibroblast population. All primary cultures were used from passages 5-10 and maintained on tissue culture plastic until the time of experiments. Two different HLF lines from different donors were used in this study.

\section{Preparation of eosinophil-conditioned media}

Peripheral blood eosinophils were cultured at $1 \times 10^{6} / \mathrm{ml}$ in medium (RPMI 1640 plus 10\% fetal bovine serum (FBS)) with IL-3 (2 ng/ml) or IL-5 (4 ng/ml) for $20 \mathrm{~h}$. After $20 \mathrm{~h}$ stimulation with cytokines, eosinophils were washed and suspended at $1 \times 10^{6} / \mathrm{ml}$ in fresh medium (no cytokine), and $1 \mathrm{ml}$ was added to a 24-well plate, which had been coated overnight with HA-IgG $(10 \mu \mathrm{g} / \mathrm{ml}$; $350 \mu \mathrm{l} /$ well) and saturated with $0.1 \%$ gelatin for $30 \mathrm{~min}$ at $37^{\circ} \mathrm{C}$. Heat aggregation of human IgG (HA-IgG) was performed in PBS for $30 \mathrm{~min}$ at $63{ }^{\circ} \mathrm{C}$, as previously described [29]. IL-3-preactivated eosinophils were also seeded on uncoated (no HA-IgG) wells, as negative control for eosinophil degranulation. After a $6 \mathrm{~h}$ incubation, the three types of supernatant fluids (conditioned media: IL-3, IL-3 on HA-IgG (IL3IgG) and IL-5 on HA-IgG (IL5IgG)) were harvested and stored at $-80{ }^{\circ} \mathrm{C}$, before analysis by ELISA for EDN release (degranulation), and before addition on cultured HLF. Human EDN ELISA (MBL, Woburn, MA) has a minimum detection limit of $0.62 \mathrm{ng} / \mathrm{ml}$.
Fibroblasts cultured with eosinophil-conditioned media HLF were treated in 1:1 dilution of maintenance media (DMEM/10\% FBS, $2 \mathrm{mM}$ L-glutamine, and antibiotics as above) and eosinophil-conditioned media. The three types of eosinophil-conditioned media described above (IL-3, IL-3 on HA-IgG (IL3IgG) and IL-5 on HA-IgG (IL5IgG)) were obtained from three different blood donors. Each conditioned medium was tested individually on the HLF from both lung biopsy donors. Controls included HLF cultured in medium only (RPMI with 5\% FBS) and HLF cultured with $1 \mathrm{ng} / \mathrm{ml}$ plus $0.5 \mu \mathrm{g} / \mathrm{ml}$ of HA-IgG (rhIL3IgG). This latter control was used to account for 1) potential release of intracellular IL-3 during IL-3-activated eosinophil degranulation, and 2) any release of coated HA-IgG during the 6 h degranulation period. After $24 \mathrm{~h}$, HLF were harvest with RLT extraction buffer from Qiagen for total RNA extraction.

\section{RNA preparation and RNA-seq analysis}

Total RNA was extracted from HLF using the RNeasy Mini Kit (Qiagen, Valencia, CA) and treated with DNase (RNase-free DNase kit, Qiagen). Fifteen $\mu \mathrm{l}$ of total RNA were recovered with concentrations ranging from 70 to $180 \mathrm{ng} / \mu \mathrm{l}$ and with ratios $260 /$ $280 \mathrm{~nm}$ ranging from 1.98 to 2.04. RNA samples were submitted to the University of WisconsinMadison Biotechnology Center (Madison, WI) for RNA quality and integrity evaluation via Agilent 2100 Bioanalyzer platform (Agilent Technologies) and whole-transcriptome sequencing. The sequencing library from mRNA was prepared using TruSeq Stranded mRNA Library Preparation Kit (Illumina; San Diego, CA, USA) and RNA-seq $(1 \times 100$ bases $)$ was carried out using Illumina HiSeq 2500 platform. SeqMan Ngen (v.13) and ArrayStar with Qseq module (v.13) software packages (DNAStar, Madison, WI) were used to map sequence reads to human reference genome (GRCh38), apply statistical analyses and identify global gene expression changes for both fibroblast donors. Of note, the two fibroblasts (L20 and L21) were analyzed separately, and only genes up- or down-regulated by more than 1.5 fold for both L20 and L21 were considered in our analyses. Raw data and normalized RPKM (Reads Per Kilobase per Million mapped reads) values have been deposited to the NCBI Gene Expression Omnibus (GEO) database and assigned accession number (GSE102860). Differentially expressed genes were analyzed using DAVID Bioinformatics Resources 6.8(Beta) (National Institute of Allergy and Infectious Diseases (NIAID), NIH) [32] and the Ingenuity Pathway Analysis (IPA) web-based software (Qiagen) to identify the relevant biological mechanisms and pathways. 
Real-time quantitative (q) PCR

The reverse transcription reaction was performed using the Superscript III system (Invitrogen/Life Technologies, Grand Island, NY, USA). Gene expression levels were determined by qPCR using SYBR Green Master Mix (SABiosciences, Frederick, MD, USA) or Taqman. For PCR using SYBR Green, forward and reverse specific primers (see Additional file 1: Table E1 for primer sequences) were designed using Primer Express 3.0 (Applied Biosystems, Carlsbad, CA, USA) and blasted against the human genome to determine specificity using http://www.ncbi.nlm.nih.gov/tools/primer-blast. The reference gene primers, ß-glucuronidase ((GUSB), forward: caggacctgcgcacaagag, reverse: agcgtgtcgacccattc), was used to normalize the samples. Standard curves were performed and efficiencies were determined for each set of primers. Efficiencies ranged between 91 and $96 \%$. Data are expressed as fold change using the comparative cycle threshold $(\Delta \Delta \mathrm{CT})$ method as described previously [29].

\section{Statistical analyses}

Statistical analyses of the pathways, potential upstream regulators and downstream functions of the genes changed by the IL3IgG conditioned media in HLF were generated by the Ingenuity Pathway Analysis (IPA) package from Qiagen. Statistical analyses of the qPCR were performed using the SigmaPlot 11.0 software package (Systat Software, Inc., San Jose, CA, USA). One Way ANOVA followed by the Holm-Sidak analysis were used to compare the three groups (IL3, IL3IgG and IL5IgG), and $p<0.05$ was considered statistically significant.

\section{Results}

\section{Generation of conditioned media from degranulated eosinophils}

Eosinophils activated for $20 \mathrm{~h}$ with IL-3 or IL-5 were added on coated heat-aggregated (HA)-human serum IgG for $6 \mathrm{~h}$ (IL3IgG and IL5IgG). The morphology of the eosinophils pre-activated with IL-3 or IL-5 and seeded on coated HA-IgG is shown on Additional file 2: Figure E1, where pictures of cultures were taken at $2 \mathrm{~h}$, $4 \mathrm{~h}$ and $6 \mathrm{~h}$. Additional file 2: Figure E1 suggests that in the earlier time-points, eosinophils adhered to HA-IgG. However, the adhesion was reversible for IL-5-activated eosinophils while IL-3 activation led to cell breaks and release of free granules (Additional file 1: Figure E1). As a negative control for eosinophil degranulation, IL-3activated eosinophils were seeded in uncoated wells (IL3). In this condition, (no IgG), eosinophils do not adhere to the bottom of the wells (not shown). Conditioned media were harvested $6 \mathrm{~h}$ after eosinophils from three donors were seeded on IgG. As shown on Fig. 1, IL3IgG eosinophils released 15 -fold more EDN than

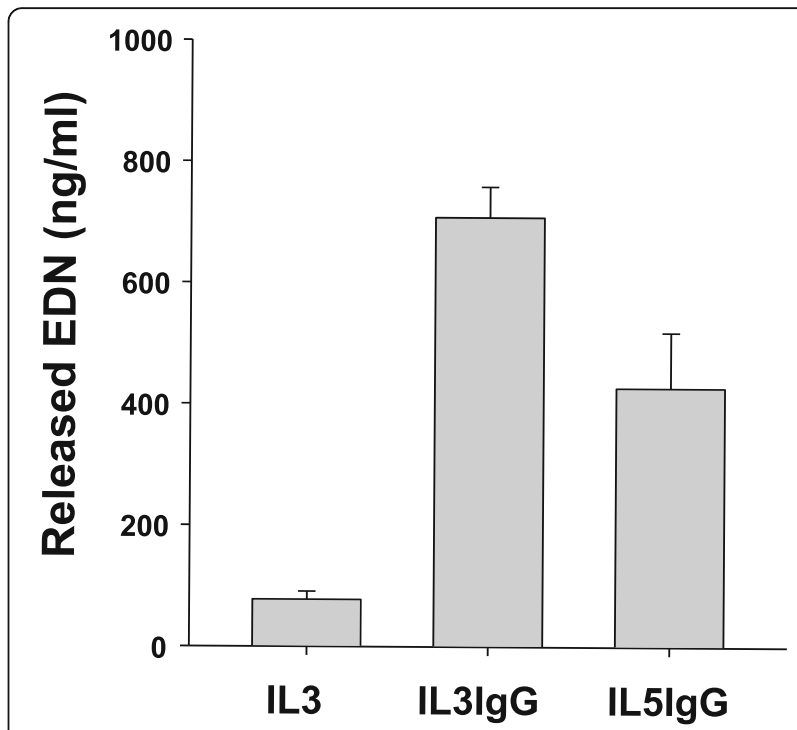

Fig. 1 Evaluation of eosinophil degranulation by the measurement of EDN in eosinophil conditioned media. To prepare the eosinophil conditioned media that will be tested on human lung fibroblasts, human blood eosinophils were activated with IL-3 or IL-5 for $20 \mathrm{~h}$ and were then added on heat-aggregated (HA) human serum IgG for $6 \mathrm{~h}$. Three conditioned media were prepared, including two conditioned media from IL-3-activated eosinophils, cultured for $6 \mathrm{~h}$ on coated HA-lgG (IL3lgG) or uncoated wells (IL3). The third

conditioned medium was from IL-5-activated eosinophils seeded for $6 \mathrm{~h}$ on HA-lgG (IL5lgG). EDN released from eosinophils in the three conditioned media was measured by ELISA. The graph is an average \pm SEM of three different cultures from three different eosinophil donors. The three groups were statistically different from each other as determine using the One-Way Analysis of Variance followed by the Holm-Sidak method $(p<0.001, n=3)$

the control IL3 (seeded on uncoated wells), and $\sim 2$-fold more than IL5IgG. These conditioned media samples were diluted (2-fold) in serum free medium, and added to human lung primary fibroblasts (HLF) for $24 \mathrm{~h}$ before RNA expression analyses by next-generation RNA sequencing (RNA-Seq) and RT-qPCR.

\section{RNA-seq analyses of HLF cultured with eosinophil conditioned media}

For RNA-seq analyses, total RNA was extracted from 2 HLF cell lines (L20 and L21) cultured for $24 \mathrm{~h}$ with conditioned media from eosinophils (from $n=2$ different donors) degranulated on HA-IgG after a $20 \mathrm{~h}$ priming with either IL-3 (IL3IgG) or IL-5 (IL5IgG). Also, HLF culture controls included HLF cultured with medium only or with $1 \mathrm{ng} / \mathrm{ml}$ of IL-3 plus $0.5 \mu \mathrm{g} / \mathrm{ml}$ of HA-IgG (rhIL3IgG) to account for the possible release of rhIL-3 from eosinophils degranulating on HA-IgG, and for the possible detachment of coated IgG during degranulation.

In a first analysis, we wished to examine gene expression levels changed in HLF by the degranulation products from IL-3-activated eosinophils. For this purpose, 
gene expression by fibroblasts incubated with IL3IgG conditioned media (mean values of two donors) was compared to both control fibroblast cultures (medium and rhIL3IgG). Genes whose expression level is changed in the same direction (up or down) by more than 1.5 fold in both HLF lines (L20 and L21) were included in this first dataset. Among these genes, 169 genes were upregulated (Additional file 3: Table E2). Analysis using DAVID Bioinformatics Resources identified 24 genes coding for secreted proteins (including 10 cytokines) and 47 genes coding for membrane proteins (Table 1). Additionally, 131 genes were downregulated (Additional file 4: Table E3), among them, 44 were genes coding for membrane proteins, 23 coded for nuclear proteins, while only 10 coded for secreted proteins.

The differentially expressed genes (up- (Additional file 3 : Table E2) and down-regulated (Additional file 4: Table E3)) were analyzed using the Ingenuity Pathway Analysis (IPA) web-based software. The Predictive Causal Analytic tool identified three major and highly overlapping Regulator Effect Networks. These three networks contained part of the 300 genes present in our dataset (target molecules), potential upstream regulators of these genes, and the association between these genes with potential downstream biological functions (Table 2). More than 15\% (27) of the 169 genes upregulated in our dataset were part of the target genes grouped into the three networks. There was $85 \%$ similarity among the target genes between the three networks. Around $80 \%$ of the potential identified upstream regulators (Table 2) were common among the three networks, and more than $65 \%$ of the projected functional downstream effects of these genes were similar between the three networks as well. Therefore, the aggregate of all three networks is shown in Table 2. The main predicted downstream functions of the fibroblast genes were related to the immune response, tissue remodeling and lipid metabolism (Table 2).

The upstream regulators are molecules that are predicted to activate or inhibit the expression of the genes in our dataset, according to the literature compiled in the Ingenuity database. IPA determined the predicted overlap between an upstream regulator and the genes listed in our dataset. Additionally, IPA uses a z-score algorithm to make statistical prediction for activation or inhibition of a specific upstream regulator to genes present in our dataset. As shown in Table 3, the main significant groups of upstream regulators are composed of cytokines, kinases, intracellular signaling molecules

Table 1 Genes upregulated by >1.5-fold in both HLF lines (L20 and L21) at $24 \mathrm{~h}$, by degranulated products from eosinophils pre-activated with IL-3 for $20 \mathrm{~h}$ and seeded on coated HA-IgG (IL3lgG) for $6 \mathrm{~h}$, from two different eosinophil donors, compared to HLF controls cultured with medium only, and with rhlL-3 $(1 \mathrm{ng} / \mathrm{ml})$ plus soluble HA-lgG $(1 \mu \mathrm{g} / \mathrm{ml})$

Secreted Proteins Apolipoprotein A-I (APOA1); bone morphogenetic protein 8b (BMP8B); C-C motif chemokine ligand 2 (CCL2); chemokine (C-C motif) ligand 4-like 2 (CCL4L2); chondroadherin like (CHADL); collagen type IV alpha 3 (COL4A3); complement component 1, q subcomponent-like 1 (C1OL1); complement component 3 (C3); complement component 8 alpha subunit (C8A); C-X-C motif chemokine ligand 1 (CXCL1); C-X-C motif chemokine ligand 8 (CXCL8); fibroblast growth factor 10 (FGF10); fibronectin leucine rich transmembrane protein 1 (FLRT1); gremlin 2, DAN family BMP antagonist (GREM2); interleukin 32 (IL32); interleukin 6 (IL6); Klotho (KL); mannosyl (alpha-1,3-)-glycoprotein beta-1,4-Nacetylglucosaminyltransferase, isozyme A (MGAT4A): nodal growth differentiation factor (NODAL); platelet factor 4 variant 1 (PF4V1); plexin domain containing 1 (PLXDC1); secreted and transmembrane 1 (SECTM1); SPARC like 1 (SPARCL1); urocortin 2 (UCN2)

Membrane proteins ADAM metallopeptidase domain 20 (ADAM20); ATPase phospholipid transporting 8B4 (ATP8B4); bone marrow stromal cell antigen 2 (BST2); carnitine palmitoyltransferase 1B (CPT1B); CD177 molecule (CD177); cholesterol 25-hydroxylase (CH25H); complement component 8 alpha subunit (C8A); chromosome 1 open reading frame 204 (C1orf204); chromosome 2 open reading frame 82 (C2orf82); cytochrome P450 family 1 subfamily A member 1 (CYP1A1); cytochrome P450 family 1 subfamily B member 1 (CYP1B1); dachsous cadherin-related 2 (DCHS2); fibronectin leucine rich transmembrane protein 1 (FLRT1); G protein-coupled receptor 17 (GPR17); galactose-3-O-sulfotransferase 2 (GAL3ST2); glutamyl aminopeptidase (ENPEP); guanine nucleotide binding protein (G protein), gamma 3 (GNG3); immunoglobulin superfamily member 6 (IGSF6); intercellular adhesion molecule 1 (ICAM1); interleukin 12 receptor subunit beta 1 (IL12RB1); Janus kinase 3 (JAK3); Klotho (KL); mannosyl (alpha-1,3-)-glycoprotein beta-1, 4-N-acetylglucosaminyltransferase, isozyme A (MGAT4A); NPC1-like 1 (NPC1L1); NTPase, KAP family P-loop domain containing 1 (NKPD1) nucleoporin 210 kDa (NUP210); PAPPA antisense RNA 1 (PAPPA-AS1); par-6 family cell polarity regulator beta (PARD6B); plexin domain containing 1 (PLXDC1); potassium voltage-gated channel modifier subfamily S member 2 (KCNS2); protein tyrosine phosphatase, receptor type N2 (PTPRN2); RAB9B, member RAS oncogene family (RAB9B); receptor (chemosensory) transporter protein 4 (RTP4); reticulon 1 (RTN1); secreted and transmembrane 1 (SECTM1); shroom family member 2 (SHROOM2); solute carrier family 1 member 3 (SLC1A3); solute carrier family 16 member 6 (SLC16A6); solute carrier family 18 member A2 (SLC18A2); solute carrier family 22 member 14 (SLC22A14); solute carrier family 51 alpha subunit (SLC51A); sortilin related VPS10 domain containing receptor 2 (SORCS2); synapse differentiation inducing 1 (SYNDIG1); TBC1 domain family member 3H (TBC1D3H); TMEM110-MUSTN1 readthrough (TMEM110-MUSTN1); V-set and immunoglobulin domain containing 10 like (VSIG10L); zinc finger CCCH-type containing $12 \mathrm{~A}(\mathrm{ZC} 3 \mathrm{H} 12 \mathrm{~A})$

Nuclear proteins Apolipoprotein A-I (APOA1); brain expressed X-linked 2 (BEX2); calmodulin like 6 (CALML6); cell death inducing DFFA like effector c (CIDEC); cilia and flagella associated protein 46 (CFAP46); distal-less homeobox 1 (DLX1); ETS homologous factor (EHF); family with sequence similarity 71 member E1 (FAM71E1); fibroblast growth factor 10 (FGF10); forkhead box D2 (FOXD2); hes family bHLH transcription factor 1 (HES1); histone cluster 1, H2bi (HIST1H2BI); histone cluster 2, H2be (HIST2H2BE); histone cluster 2, H3d (HIST2H3D); inhibitor of CDK, cyclin A1 interacting protein 1 (INCA1); LIM homeobox 4 (LHX4); NFKB inhibitor alpha (NFKBIA); NFKB inhibitor zeta (NFKBIZ); par-6 family cell polarity regulator beta (PARD6B); phosphatase domain containing, paladin 1 (PALD1); SRY-box 7 (SOX7); ubiquitin specific peptidase 17-like family member 1 (USP17L1); vitamin D (1,25-dihydroxyvitamin D3) receptor (VDR); v-rel avian reticuloendotheliosis viral oncogene homolog B (RELB); zinc finger CCCH-type containing 12A (ZC3H12A); zinc finger MYND-type containing 15 (ZMYND15); ZNF559-ZNF177 readthrough (ZNF559-ZNF177) 
Table 2 Regulator Effect Networks identified by Ingenuity Pathway Analysis (IPA) using the 300 genes of our first dataset (Additional file 3: Table E2 and Additional file 4: Table E3). Summation of all three identified networks

\begin{tabular}{l}
\hline Upstream Regulators (61) \\
\hline Akt, APP, C5, CAMP, CCL11, CD4OLG, CHUK, EGR1, ERK, F2, FN1, GFI1, HMGB1, HMOX1, IFNG, IKBKB, IL1, \\
IL17A, IL17F, IL18, IL1A, IL1B, IL27, IL32, IL6, Interferon alpha, JAK2, Jnk, JUN, MAPK14, MAPKAPK2, MEOX2, \\
MYD88, NFAT (complex), NFKB (complex), NfkB-ReIA, NfKB1-ReIA, OSM, PPAR $\alpha$-RXR, , PRKCD, PSMD10, PTGS2, \\
REL, RELA, SELP, SELPLG, STAT1, STAT3, TBK1, TICAM1, TIr, TLR2, TLR4, TLR7, TNF, TNFRSF18, TNFRSF1A, \\
TNFSF12, TRADD, TRAF6, VCAN \\
\hline Target Molecules from our First Dataset (32) \\
\hline APOA1, BEX2, C3, CCL2, CH25H, COL4A3, CXCL1, CXCL8, CYP1A1, CYP1B1, EGR3, ENPEP, ERBB3, FGF10, HES1, \\
ICAM1, IL12RB1, IL6, JAK3, KL, LGALS9B, MBP, NFKBIA, NFKBIZ, NPTX1, PILRA, RELB, SLC1A3, SQSTM1, \\
TNFRSF25, VDR, ZC3H12A \\
\hline Downstream Functions \\
\hline Immune Response: \\
- Activation: activation of antigen presenting cells, activation of phagocytes, immune response of \\
phagocytes, response of myeloid cells, inflammation of airway, differentiation of lymphatic system \\
cells, adhesion of immune cells \\
- Cell movement and chemotactism: cell movement of macrophages, cell movement of monocytes, \\
cell movement of neutrophils, cell movement of T lymphocytes, cellular infiltration of phagocytes, \\
migration of granulocytes, recruitment of macrophages, migration of antigen presenting cells, \\
chemotaxis of cells \\
Remodeling: angiogenesis, binding of endothelial cells, development of connective tissue cells, \\
formation of osteoclasts, resorption of bone \\
Lipid Metabolism: synthesis of lipid, steroidogenesis of hormone \\
Others: activation of tumor cell lines, mobilization of Ca2+, uptake of 2-deoxyglucose
\end{tabular}

Genes upregulated and downregulated in our dataset (Additional file 1: Table E1 and Additional file 3: Table E2)

and transcription regulators. The upstream regulators with the four highest $\mathrm{z}$-scores for each group is shown in Table 3. Furthermore, other potential significant upstream regulators are listed on Additional file 5: Table E4. Of note and as expected, kinase inhibitors for MAPK, NF-kB, PI3K display negative z-scores predicting inhibitory effects on the target genes (Additional file 4: Table E3). In addition to these potential upstream regulators shown in Table 3, Additional file 4: Table E3 and Additional file 5: Table E4, miR-223 (z-score $\left.=-2.0 ; p=8.51 \times 10^{-3}\right)$ was also found to be a potential upstream down-regulator of $A B C A 13, A K 8$ and EGR3 (Additional file 6: Table E6). This is particularly interesting in the light of a recent report by Zangari et al. where it is shown that neutrophils release miR-223-3p via extracellular vesicles [33]. Notably also, miR-223 expression was increased in bronchoalveolar lavage cells enriched in airway eosinophils $48 \mathrm{~h}$ after a segmental allergen challenge [34]. Subsequently, we tested the validity of these upstream regulators by analyzing the expression of the upstream regulator receptors on HLF. For this purpose, we extracted and listed the expression level of receptors for the upstream regulators predicted by IPA from our RNA-seq database. This is shown in Table 2, Table 3 and Additional file 4: Table E3. As shown in Additional file 7: Table E5, HLF expressed relatively high levels of the receptors for TNF- $\alpha$, IL-1, OSM, IL6 , IFN- $\gamma$, IL-17A, IL-17F, IL-27, IFN- $\alpha$, TNFSF12, C5 and F2. Of note, while IL2RG (common $\gamma$-chain receptor) is not expressed, IL-4 can signal via its type II receptor, whose subunits IL4R and IL13RAI are both expressed by HLF (Additional file 7: Table E5). In addition to IL2RG, the receptors for GM-CSF and IL18 were not expressed in HLF, in any of our conditions (Additional file 7: Table E5). Notably also, while IL-3activated eosinophils may be the source of these upstream regulators, HLF might also release some of these regulators during the $24 \mathrm{~h}$ culture with eosinophil conditioned media. Therefore, the potential upstream regulators that are extracellularly localized and expressed by HLF were listed in Additional file 7: Table E5. HLF express IL6, TNFSF12, C5, IL32, FN1, APP, HMGB1 and TLR4 (Additional file 7: Table E5), which could all participate in HLF activation in an autocrine way. Eosinophils can produce and/or store a variety of cytokines and other ligands 
Table 3 Upstream Regulators of the genes listed in our dataset (target genes, Additional file 3: Table E2 and Additional file 4: Table E3) as predicted by IPA analysis

\begin{tabular}{|c|c|c|c|c|}
\hline \multirow{2}{*}{$\begin{array}{l}\text { Upstream } \\
\text { regulator }\end{array}$} & \multirow{2}{*}{$\begin{array}{l}P \text { value of } \\
\text { overlap }\end{array}$} & \multirow{2}{*}{$\begin{array}{l}\text { Activation } \\
z \text {-score }\end{array}$} & \multicolumn{2}{|l|}{ Target genes listed in our dataset } \\
\hline & & & Genes upregulated & Genes downregulated \\
\hline \multicolumn{5}{|l|}{ Cytokine } \\
\hline TNF & $2.8610^{-4}$ & 3.788 & $\begin{array}{l}\text { APOA1, BST2, C3, CCL2, CH25H, CIDEC, COL4A3, CPT1B, CXCL1, CXCL8, CYP1A1, } \\
\text { CYP1B1, DLX1, EHF, FGF10, HES1, ICAM1, IL32, IL6, KL, KYNU, LGALS9B, NFKBIA, } \\
\text { NFKBIZ, RELB, SLC1A3, SQSTM1, VDR, ZC3H12A (29) }\end{array}$ & \\
\hline IL1B & $2.6110^{-3}$ & 3.059 & $\begin{array}{l}\text { C1R, C3, CCL2, CXCL1, CXCL8, CYP1A1, EHF, HES1, ICAM1, IL32, IL6, LGALS9B, } \\
\text { NFKBIA, NFKBIZ, RELB, SLC1A3, VDR, ZC3H12A (18) }\end{array}$ & \\
\hline OSM & $7.7110^{-3}$ & 2.853 & C1R, CCL2, CH25H, CXCL1, CXCL8, CYP1B1, ICAM1, IL32, IL6, SLC16A6, VDR (11) & ERBB3 \\
\hline IL6 & $1.1510^{-2}$ & 2.824 & $\begin{array}{l}\text { APOA1, BST2, C3, CCL2, CXCL1, CXCL8, CYP1A1, CYP1B1, ICAM1, IL6, NFKBIA, } \\
\text { USP17L1 (12) }\end{array}$ & TNFRSF25, TLR1 \\
\hline \multicolumn{5}{|l|}{ Signaling } \\
\hline NFkB (complex) & $1.2010^{-3}$ & 3.746 & $\begin{array}{l}\text { BEX2, C1R, C3, CCL2, CXCL1, CXCL8, EHF, ICAM1, IL32, IL6, KYNU, NFKBIA, } \\
\text { NFKBIZ, RELB, ZC3H12A (15) }\end{array}$ & \\
\hline MYD88 & $3.3110^{-7}$ & 3.081 & $\begin{array}{l}\text { C3, CCL2, CH25H, CXCL1, CXCL8, FGF10, ICAM1, IL32, IL6, NFKBIA, NFKBIZ, } \\
\text { RELB, ZC3H12A (13) }\end{array}$ & PILRA \\
\hline Akt (group) & $1.0010^{-2}$ & 2.574 & CCL2, CXCL8, HES, IL32, IL6, KL & ERBB3 \\
\hline ERK (group) & $9.6010^{-3}$ & 2.559 & CCL2, CXCL8, CYP1A1, ICAM1, IL6, KYNU, NFKBIZ & \\
\hline \multicolumn{5}{|l|}{ Transcription Factor } \\
\hline JUN & $1.0810^{-4}$ & 3.097 & $\begin{array}{l}\text { CCL2, CXCL1, CXCL8, CYP1B1, HES1, ICAM1, IL6, NFKBIA, NFKBIZ, PARD6B, } \\
\text { RELB, VDR (12) }\end{array}$ & MBP, PAK3, \\
\hline RELA & $3.5510^{-5}$ & 2.863 & $\begin{array}{l}\text { BEX2, C3, CCL2, CXCL1, CXCL8, CYP1A1, EHF, FGF10, HES1, ICAM1, IL32, } \\
\text { IL6, NFKBIA, RELB (14) }\end{array}$ & \\
\hline STAT1 & $3.0510^{-2}$ & 2.574 & C3, CCL2, CH25H, CXCL8, HES, ICAM1, IL6 & \\
\hline STAT3 & $1.6710^{-2}$ & 2.439 & BEX2, BST2, CCL2, CXCL8, ICAM1, IL12RB1, IL6, NFKBIZ, SLC1A3, VDR & EGR3 \\
\hline
\end{tabular}

[35]. While we have not yet performed transcriptome and proteome of IL-3-activated eosinophils, we have recently reported RNA-seq data using resting human blood eosinophils [36]. In that study, among the potential upstream regulators identified by IPA, transcripts coding for CAMP (LL37), CHUK, HMGB1, HMOX1, IL-1, IL-18, IL-32, OSM, SELPG and TNFSF12, were detected in eosinophils. Therefore, altogether, our data indicate that IL-1ß, OSM (oncostatin-M), IL-32 and TNFSF12 (Tweak) may be candidates to explain the direct effect of conditioned medium from degranulated eosinophils on HLF. Interestingly, IL32 was upregulated in fibroblasts by IL3IgG conditioned media (Additional file 7: Table E5), suggesting that IL-32 could function endogenously on fibroblasts.

The downstream analysis performed by IPA shows a variety of downstream functions affected by the proteins coded by the genes composing our dataset. As shown in Table 2, downstream functions of 32 genes from our dataset as defined by the Regulator Effect Networks have been regrouped in three major categories: immune response, tissue remodeling and lipid metabolism. Identical to the Regulator Effect Networks (Table 2), another IPA tool called, Downstream Analysis as Networks, identified two major downstream networks, which are linked to the immune response (Fig. 2). These two networks (immune response of cells and homing of cells) are predicted to be regulated by 27 of the 300 genes present in our dataset (Additional file 1: Table E1 and Additional file 3: Table E2), with relatively high positive z-scores (3.180 and 3.407; Fig. 2). In addition to these two networks, angiogenesis, development of vasculature and development of connective tissue cells, are three major mechanistic networks characterizing tissue remodeling (Fig. 3). These three mechanistic networks include as many as 29 genes from our dataset $(\sim 10 \%)$. Finally, a third mechanistic network, named synthesis of lipid, is affected by 19 genes of our dataset and is illustrated on Fig. 4.

IPA network algorithm also generates networks showing interactions between the genes of our dataset in relation with other neighboring genes present in a Global Molecular Network. Thirty-five total genes, or group of genes, are present in each network. Fifteen networks were formed using $>10$ genes from our dataset. The networks with the two highest scored $\left(p\right.$-value $\left.<10^{-23}\right)$ and including $>15$ genes/groups from our dataset are shown on Additional file 8: Figure E2 and Additional file 9: Figure E3. These 15 genes or gene products are directly 


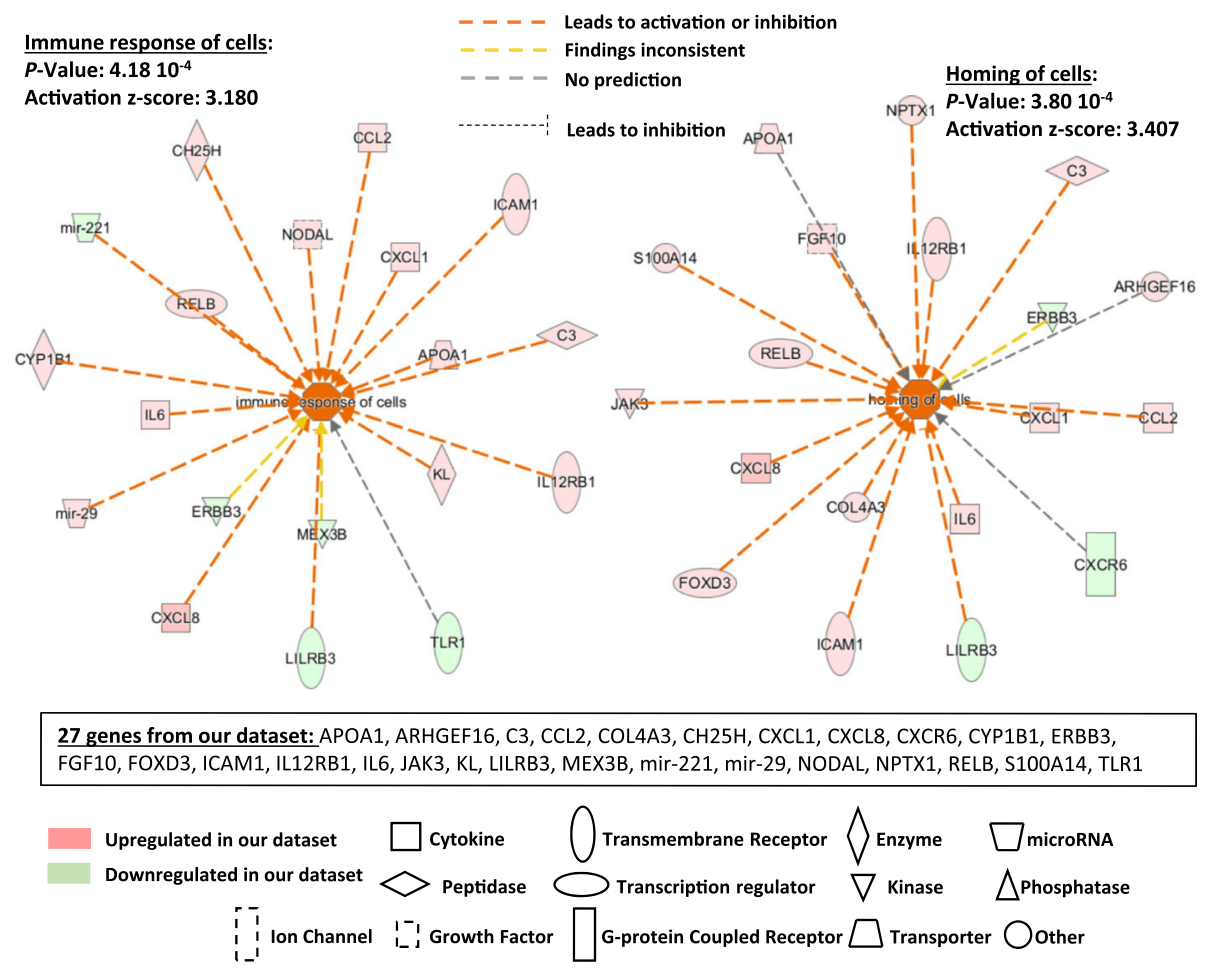

Fig. 2 IPA Downstream Analysis as Networks identified functions on the immune response. The association between genes of our dataset \#1 (300 genes) and specific downstream functions received an overlap $p$ value and a $z$-score for prediction of activation or inhibition on the functions: "immune response of cells" and "homing of cells". Twenty-seven genes from our dataset either upregulated or downregulated in HLF by IL3lgG eosinophil conditioned media, are involved in the regulation of "immune response of cells" and "homing of cells" with a significant z-score toward increased "activation"

or indirectly associated with the protein kinase $\mathrm{B}$ (PKB or Akt) (Additional file 8: Figure E2) or the cjun N-terminal protein kinase (JNK) and TGF- 3 (Additional file 9: Figure E3), and mostly characterized by the inflammatory response, cell movement and cell/tissue development. Of note, the functional networks created by IPA analysis (Additional file 8: Figs. E2 and Additional file 9: Figure E3) suggest that there is no known tight functional connection either between the 27 genes characterizing "inflammation" (Fig. 2), or between the 29 genes characterizing "tissue remodeling" (Fig. 3) or between the 19 genes characterizing "lipid metabolism" (Fig. 4). Although it is worth noticing that the network 1 (Additional file 8: Figure E2) includes IL12RB1, mir-221, mir-29 and $N O D A L$ that are all part of the 27 genes related to inflammation. In addition, the network 2 (Additional file 9: Figure E3) includes $A P O A 1, C 3, C O L 4 A 3, C Y P 1 B 1$ and FGF10 that are part of tissue remodeling, and $A D H 1 C$, $A P O A 1, C 3$ and $C Y 1 B 1$ that are all part of the genes characterizing lipid metabolism. This indicates that there are some known functional relationships between genes characterizing "Inflammation", "tissue remodeling" or "lipid metabolism" (Figs. 2, 3 and 4).
In a second analysis of our RNA-seq database, we restricted the list of genes obtained in the first dataset by eliminating the genes which expression levels were not changed in HLF cultured with IL-3- compared to IL-5activated eosinophils (IL3IgG versus IL5IgG). For this purpose, gene expression by HLF incubated with IL3IgG conditioned media (average of two donors) for $24 \mathrm{~h}$ was compared to fibroblast incubated with IL5IgG conditioned media (average of two donors), and to both controls HLF (medium and rhIL3IgG). Genes whose expression level changed by more than 1.5 -fold in the same direction (up or down) in both HLF lines are included in this second restricted dataset. In these comparisons, 35 genes coding for known proteins were upregulated (Table 4), and analysis using DAVID Bioinformatics Resources 6.8 identified eight genes coding for secreted proteins (also shown in Table 1). In addition, in this dataset \#2, 37 genes were downregulated (Additional file 6: Table E6), among them, three were genes coding for secreted proteins. Table 4 and Additional file 6: Table E6 give a brief description of the 72 (35 up +37 down) genes and their relationship with the networks created by IPA using the 300 genes in our dataset \#1 (Tables 2 and 3; Figs. 2, 3 and 4, 


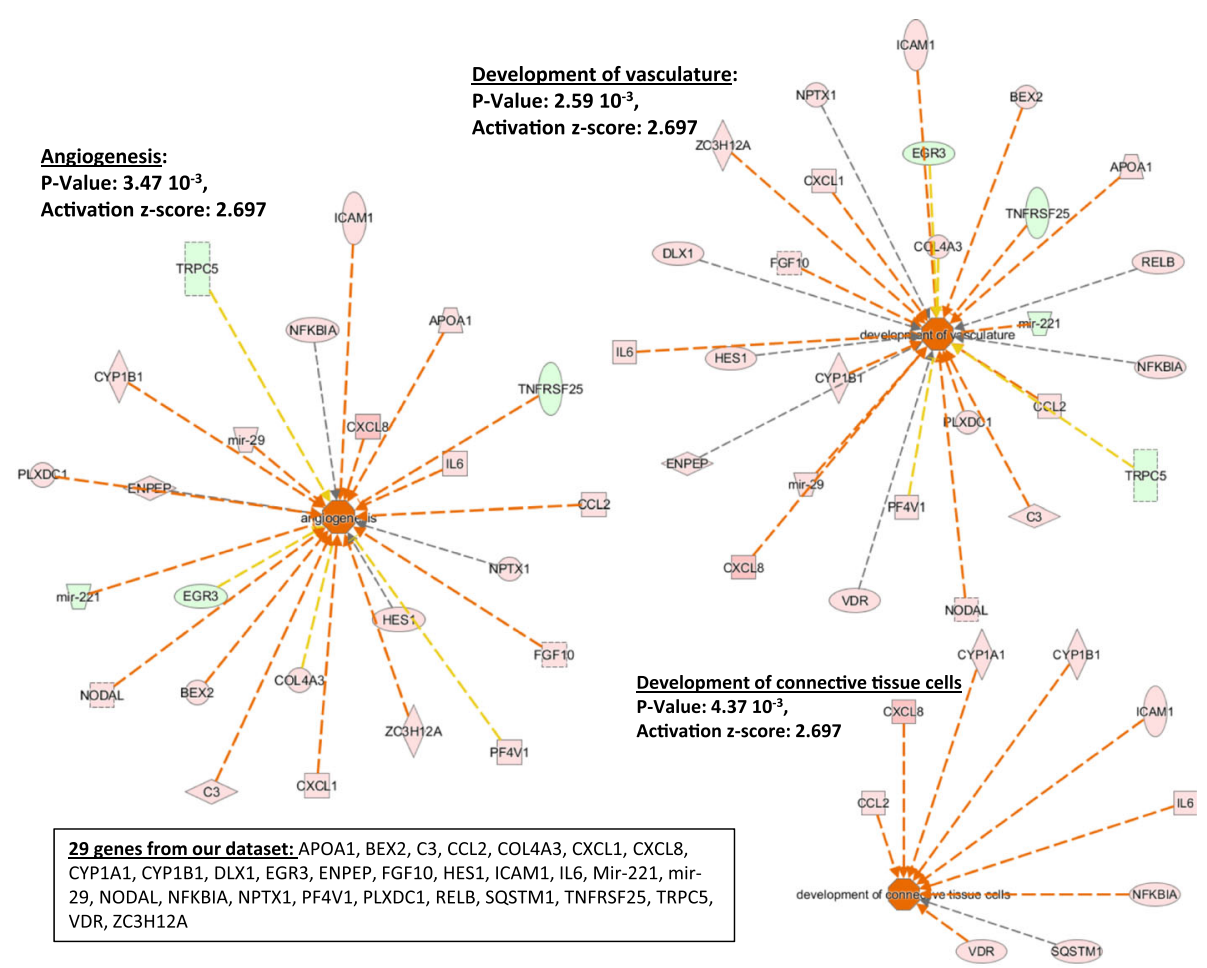

Fig. 3 IPA Downstream Analysis as Networks identified functions on tissue remodeling. The association between genes of our dataset \#1 (300 genes) and specific functions received an overlap $p$ value and a $z$-score for prediction of activation or inhibition on the functions: "angiogenesis" and "development of vasculature" and "development of connective tissue cells". Twenty-nine genes from our first dataset either upregulated or downregulated in HLF by the IL3lgG eosinophil conditioned media, are involved in the regulation of these three functions with a significant $z$-score toward increased "activation"

Additional file 2: Figure E1 and Additional file 8: Figure E2). Furthermore, Additional file 10: Table E7 shows the genes of our dataset \#2 associated with the six most significant global molecular networks formed by IPA (Additional file 8: Figure E2, Additional file 9: Figure E3 and not shown). The genes of our dataset $\# 2$, which are part of the three downstream functional categories (immunity, remodeling and lipid metabolism, Figs. 2, 3 and 4), are listed in Table 5. The eight genes shown in Table 5 are involved in at least one of these three categories, and four genes (C3, CXCL1, $C X C L 8, I L 6)$ are part of all three categories. From Table 5, CXCL1, CXCL8, ICAM1 and IL6 were arbitrarily selected to validate our RNA-seq analyses by RT-qPCR.

For RT-qPCR analysis, conditioned media (IL3IgG, IL5IgG and IL3 (no IgG)) from all three eosinophil donors were used on the two HFL lines. Controls included fibroblasts cultured in medium only and fibroblasts cultured with $1 \mathrm{ng} / \mathrm{ml}$ of IL-3 plus $0.5 \mu \mathrm{g} / \mathrm{ml}$ of HA-IgG (rhIL3IgG). In agreement with the RNA-seq data, qPCR data (Fig. 5) confirms that CXCL1, CXCL8, ICAM1 and IL6 are all significantly upregulated by IL3IgG conditioned media compared to IL5IgG and controls.

\section{Discussion}

Our study shows that expression level of $\sim 300$ genes is changed in cultured human lung primary fibroblasts (HLF) by conditioned media obtained from degranulated eosinophils. Among these genes, the Ingenuity Pathway Analysis (IPA) identified at least 66 genes known to be associated with either inflammation (immune response, homing of cells), tissue remodeling (angiogenesis, vasculature, connective tissue development), or lipid synthesis. Furthermore, among this first dataset of 300 genes, we have found a unique gene set that characterizes the activation of fibroblasts by conditioned media from IgGdriven eosinophil degranulation after pre-activation with IL-3 compared to a pre-activation with IL-5. In this gene set, we found differential expression of 72 genes (dataset \#2) coding for known proteins. According to IPA, among these 72 genes, eight of the 35 up-regulated genes, C3, CH25H, CXCL1, CXCL8, CYP1A1, ICAM1, IL6 and UCN2 are connected to inflammation, tissue remodeling or lipid synthesis, with $C 3, C X C L 1, C X C L 8$ and $I L 6$ being part of all three categories.

Increased expression levels of IL6, CXCL1 and CXCL8 have previously been observed in co-culture experiments of human blood eosinophils and fibroblasts [23, 24]. In 


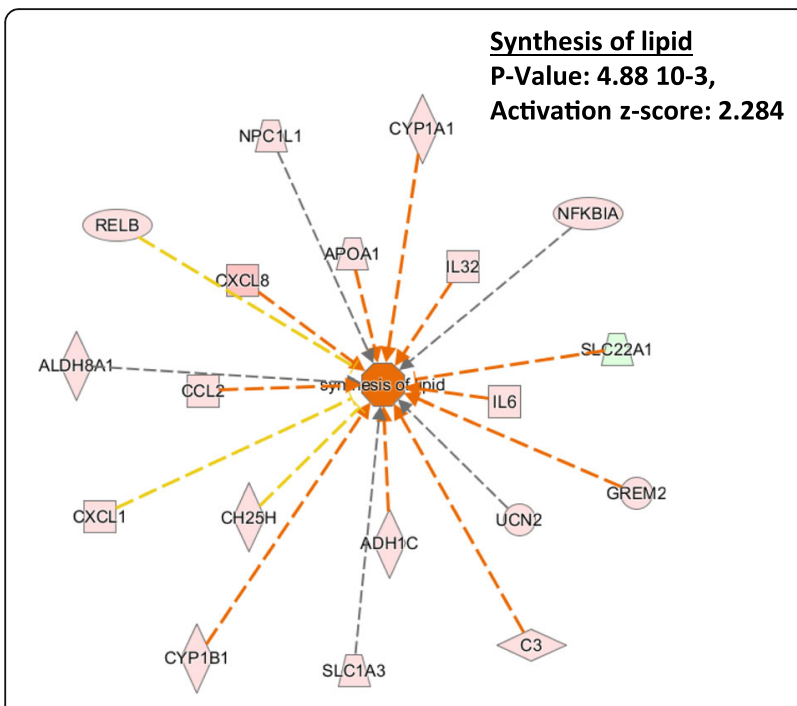

19 genes: $A D H 1 C, A L D H 8 A 1, A P O A 1, C 3, C C L 2, C H 25 H$, CXCL1, CXCL8, CYP1A1, CYP1B1, GREM2, IL32, IL6, NFKBIA, NPC1L1, RELB, SLC1A3, SLC22A1, UCN2

Fig. 4 IPA Downstream Analysis as Networks identified functions on lipid metabolism. The association between genes of our dataset \#1 (300 genes) and specific functions received an overlap $p$ value and a $z$-score for prediction of activation or inhibition on the function: "synthesis of lipid". Nineteen genes from our first dataset either upregulated or downregulated in HLF by the IL3lgG eosinophil conditioned media, are involved in the regulation of this function with a significant $z$-score toward increased "activation"

those studies, IL-6 secretion by fibroblasts was dependent on p38, ERK and NF-kB; and CXCL1 and CXCL8 inhibitions were reached by blockade of p38 and ERK [24]. In agreement with this previous publication, as identified by IPA, all these intracellular mediators (kinases and NF-kB) were significant potential upstream activators of the genes upregulated in our datasets.

C3, CXCL1, CXCL8, ICAM1 and IL-6 are all enhancers of neutrophil activation and trafficking [37-41], suggesting that one effect of IL-3-dependent activation of eosinophils is enrichment in soluble mediators that can influence fibroblasts to participate in the recruitment of a neutrophilic immune response. Although the role of the protein product of $\mathrm{C} 3$ (C3a) on neutrophils remains controversial [42], it has been previously reported that mice lacking C3 exhibit less neutrophil infiltration in brain injury and infection models [43]. Notably, the reduction of inflammatory cell, including neutrophil, recruitment in these $\mathrm{C} 3$ knock out mice, was probably at least partially due to the ability of C3a to activate endothelial cells to produce adhesion membrane receptors and to exhibit stress fiber formation [44, 45]. In addition to its role in neutrophilia, C3a can induce smooth muscle cell contraction $[46,47]$, participates in mast cell degranulation [48] and increases production of pro-inflammatory cytokines by monocytes [49]. Therefore, in addition to IL-6, CXCL1 and CXCL8 (IL-8), C3 is another factor produced by HLF in the presence of eosinophils that can mediate inflammation and remodeling.

Beyond enhancement of the neutrophilic recruitment, we also found increased production of mediators that can participate in promoting inflammation or activate fibroblasts in a paracrine/autocrine fashion. One such gene is $\mathrm{CH} 25 \mathrm{H}$. $\mathrm{CH} 25 \mathrm{H}$ codes for an enzyme, cholesterol 25-hydroxylase, a multi-transmembrane endoplasmic reticulum protein, which produces the oxysterol, 25-hydroxycholesterol (25-HC) from cholesterol. The addition of the second hydroxyl group at position 25 makes 25-HC much more hydrophilic than cholesterol. Furthermore, CYP7B1 can convert 25-HC into 7 $\alpha$, 25$\mathrm{HC}$, which as an EBI2 (GPR183) ligand triggers intracellular signaling, and increases cell migration, particularly $\mathrm{B}$ cells and eosinophil [50, 51]. Interestingly, 25-HC is increased in the airway of COPD patients, and correlates positively with neutrophilic inflammation and negatively with pulmonary function [52]. Finally, 25-HC increases the production and release of TGF- $\beta$ by fibroblasts and subsequently the production of markers of myofibroblasts, including $\alpha$-smooth muscle actin, collagen 1 and metalloproteinases [53], a finding that we have confirmed in our lab (data not shown). Therefore, $\mathrm{CH} 25 \mathrm{H}$ and its product, $25-\mathrm{HC}$ have a role in tissue remodeling. In our model, we speculate that fibroblastderived $\mathrm{CH} 25 \mathrm{H}$ could potentiate myofibroblast differentiation via the production of $25-\mathrm{HC}$.

One interesting signature found by IPA analyses suggest that the genes upregulated in HLF by EOSconditioned medium enhanced angiogenesis. Inflammation and angiogenesis are thought to be closely interdependent processes (reviewed in [54]). One of the feature of asthma pathophysiology is the development of microvascular network in lungs, with severe asthma displaying higher vascularization compared to moderate and mild asthma [55]. In asthma, increased vasculature reduces airway compliance and increases airway narrowing [56]. Therefore, EOS-activated HLF may lead to increased airway remodeling via vasculature development.

Besides inflammation and remodeling, the downstream potential function associated with lipid synthesis is also intriguing. UCN2 (urocortin-2) is one molecule linked to synthesis of lipids by IPA analysis. The receptor for UCN2, CRF2 may play an important role in mechanisms that control food intake and energy homeostasis [57-59]. Xiong Y et al. have recently reported that UCN2/UCN3 via CRF2 are responsible for hypoxia-induced lipolysis and loss of weight via a cAMP/PKA pathway in white adipose tissue [60]. 


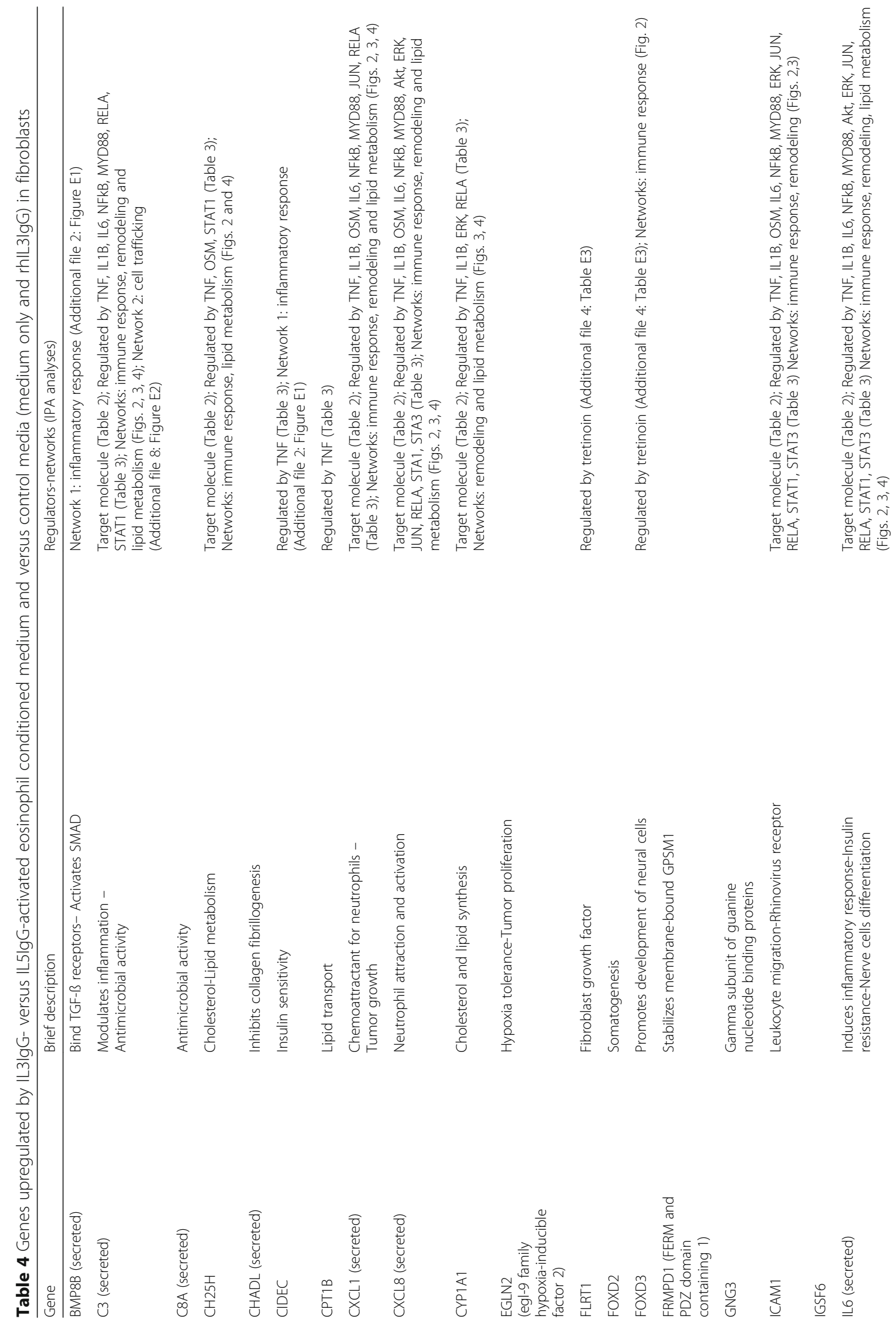




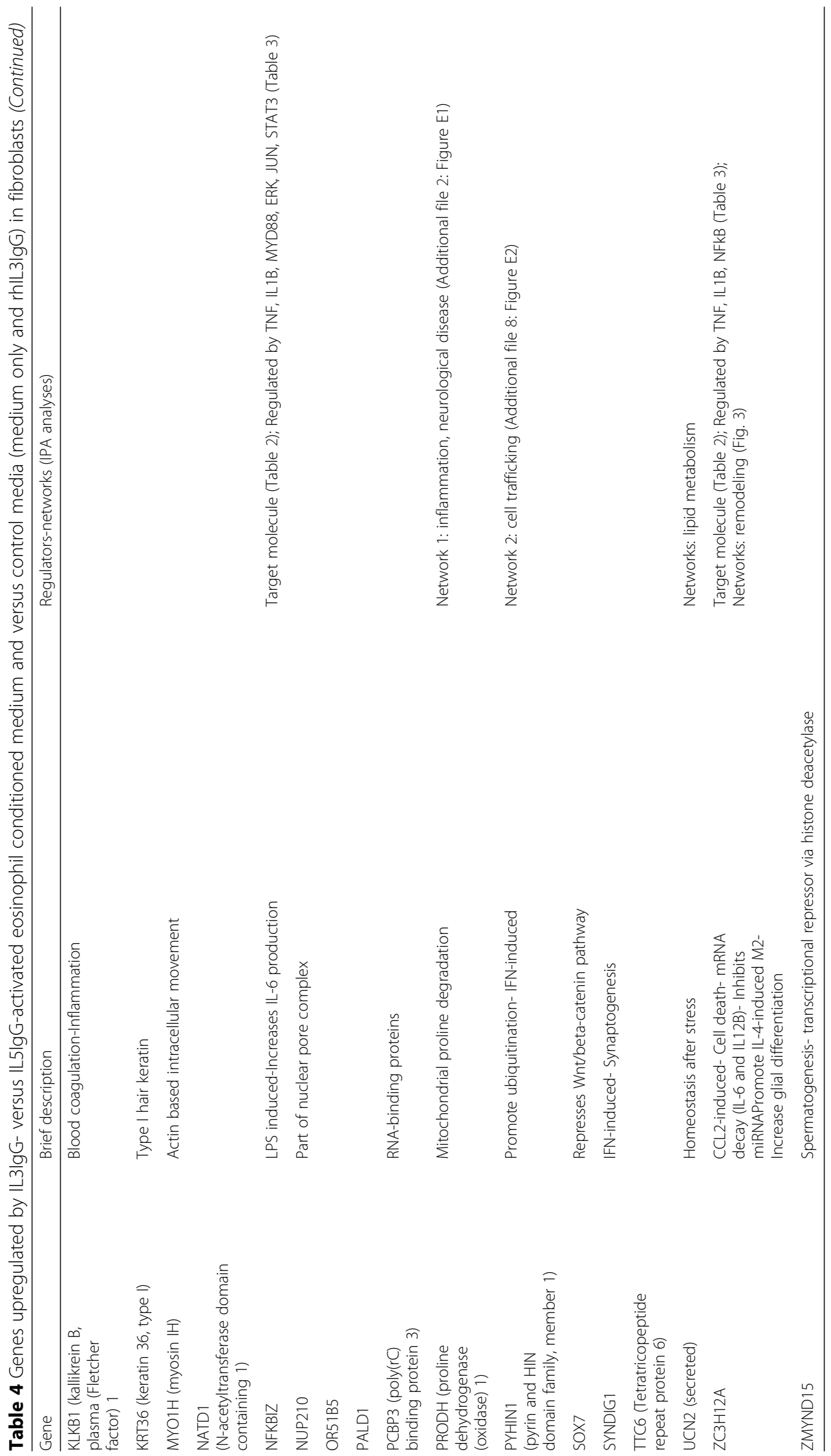



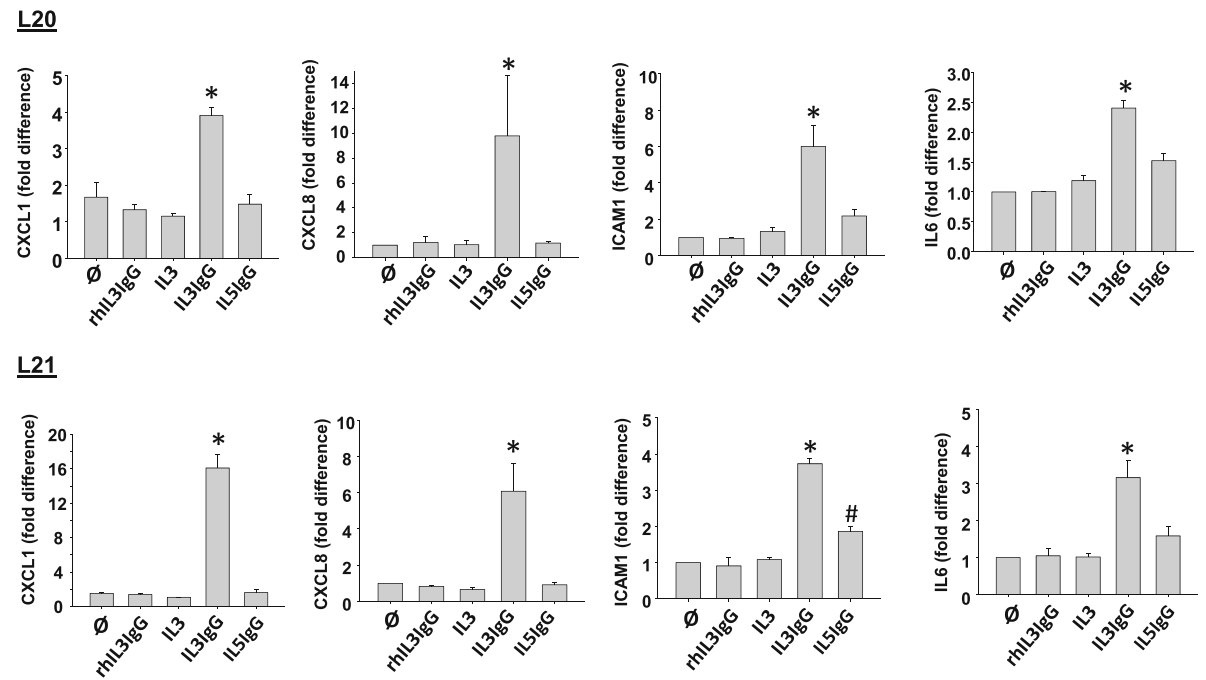

Fig. 5 PCR analysis demonstrates upregulation of CXCL1, CXCL8, IL6 and ICAM1 expression levels in HLF activated with conditioned media from eosinophils pre-activated with IL3 and degranulating on aggregated IgG. Conditioned media were prepared from eosinophils pre-activated for $20 \mathrm{~h}$ with IL-3 or IL-5, and seeded on heat-aggregated human IgG for $6 \mathrm{~h}$ (IL3lgG or IL5lgG). Conditioned media from eosinophils pre-activated with IL-3 and seeded in uncoated wells (IL3) were also prepared. HLF were cultured for $24 \mathrm{~h}$ with the three types of conditioned media (IL3lgG, IL5lgG and IL3), a control medium ( $($ ) and medium including $1 \mathrm{ng} / \mathrm{ml}$ of recombinant human IL-3 plus $0.5 \mu \mathrm{g} / \mathrm{ml}$ of HA-lgG (rhIL3/gG). RT-gPCR were performed from total mRNA extracted from two HLF lines (L2O and L21) cultured in the five different conditions. For each HLF lines, controls $(\varnothing)$ and rhIL3lgG are $n=2$. IL3, IL3lgG and IL5IgG conditioned media were prepared from three different eosinophil donors, including two donors previously used for the RNAseq analyses. IL3, IL3lgG and IL5 were compared using One Way Anova $(n=3)$, and * indicates that IL3lgG is upregulated compared to IL3 and IL5/gG; and \# indicates that IL5IgG is upregulated compared to IL3

The differential gene expression signature that we found in HLF cultured with conditioned media from IL3- compare to IL-5-pre-activated eosinophils may be explained by higher eosinophil degranulation level ([29]; Fig. 1). In addition to increased degranulation, there may be differential protein production in IL-3- versus IL-5activated eosinophils. We have recently reported that compared to GM-CSF and IL-5, IL-3 activation led to higher protein translation and production of semaphorin-7A and the low-affinity receptor for IgG (Fc-gamma-RII, CD32) [29, 61, 62]. Therefore, we speculate that compared to IL-5, eosinophils pre-activated with IL-3 further produce a subset of proteins that are potential upstream regulators of fibroblasts. IPA analysis identified a list of $\sim 60$ upstream potential regulators. We

Table 5 Genes in dataset \#2 part of the three downstream function categories defined by IPA using dataset \#1 (Table 2, Figs. 2, 3 and 4)

\begin{tabular}{|c|c|c|}
\hline \multirow{2}{*}{$\begin{array}{l}\text { Downstream function } \\
\text { categories (Figs. 2, } 3 \text { and 4) }\end{array}$} & \multicolumn{2}{|l|}{ Genes } \\
\hline & Upregulated & Downregulated \\
\hline Immune response & $\begin{array}{l}\text { C3, CH25H, CXCL1, } \\
\text { CXCL8, ICAM1, IL6 }\end{array}$ & ERBB3, TLR1 \\
\hline Remodeling & $\begin{array}{l}\text { C3, CXCL1, CXCL8, } \\
\text { CYP1A1, ICAM1, IL6 }\end{array}$ & \\
\hline Lipid synthesis & $\begin{array}{l}\mathrm{C} 3, \mathrm{CH} 25 \mathrm{H}, \mathrm{CXCL} 1, \\
\text { CXCL8, CYP1A1, IL6, UCN2 }\end{array}$ & \\
\hline
\end{tabular}

cross-referenced this list with gene expression data from our current RNA-seq and found that HLF primary lines express relatively high levels of receptors for 12 of these potential upstream regulators, including TNF- $\alpha$, IL-1, OSM (oncostatin-M), IL-6, IFN- $\gamma$, IFN- $\alpha$, TNFSF12 (tweak), C5 and F2 (thrombin). Release of soluble cytokines such as IL-1ß could account for many of the gene expression changes that we observed, as several studies have shown that eosinophils are a source of IL-1ß [1115]. Furthermore, previous co-culture experiments using neutralizing antibodies have demonstrated that anti-IL$1 ß$ inhibited $\sim 70 \%$ of eosinophil-induced IL- 6 release by fibroblasts while anti-TGF- $\beta,-$ IL- $1 \alpha$ and - TNF- $\alpha$ had lesser inhibitory effects $(\sim 20 \%)$ on IL-6 release [23]. While eosinophils are a source of TGF- $\beta[9,10]$, surprisingly TGF- $\beta$ was absent from the potential upstream regulators in our analyses. In accordance with the lack of TGF- $\beta$ in the upstream regulators, no major genes coding for markers of myofibroblast and ECM proteins were identified as induced as part of our RNA-seq datasets. Thus, it is possible that this model of degranulation on IgG does not allow piecemeal degranulation of TGF$ß$. However, it is worth noting that TGF- $\beta$ was part of a downstream Global Molecular Network (Additional file 9: Figure E3) along with collagen proteins, suggesting that fibroblast-derived autocrine or paracrine effects may ultimately lead to production of ECM components. Future studies in our lab will be needed to assess the 
components of eosinophil-derived media that mediate our observed effects.

One limitation of analyzing global gene expression changes using RNA-seq is the potential lack of correlation between transcript and protein levels due to the effects of regulation of translation, as we have previously shown for several eosinophil genes [29, 62]. Future studies that use techniques such as high-resolution mass spectroscopy proteomic technologies will help to resolve these limitations.

\section{Conclusions}

Our study has identified the gene signature in human primary lung fibroblasts that results from soluble factors released by IL-3-activated eosinophils. Global analyses indicate that a major downstream effect of this exposure is an enhancement of the expression of several genes that could promote granulocytic inflammation (C3, CXCL1, CXCL8, ICAM1 and IL6). In addition, components of this novel gene signature predict regulation of tissue remodeling, angiogenesis, and lipid metabolism. This work suggests that exposure to eosinophil-derived mediators may promote fibroblasts participation in neutrophil recruitment and airway remodeling.

\section{Additional files}

Additional file 1: Table E1. Primer sequences used for real-time PCR (DOCX $15 \mathrm{~kb}$ )

Additional file 2: Figure E1. LL-3-pre-activated eosinophils strongly adhere to coated $\mathrm{HA}-\mathrm{lg} \mathrm{g}$ and ultimately release free granule proteins. Human blood eosinophils were activated with IL-3 or IL-5 for $20 \mathrm{~h}$ and were then added on heat-aggregated (HA) human serum IgG. Photomicroscopy of IL-3 and IL-5-pre-activated eosinophils on HA-lgG was performed at $2 \mathrm{~h}$, $4 \mathrm{~h}$ and at $6 \mathrm{~h}$, using a digital camera from Olympus. (PDF $223 \mathrm{~kb}$ )

Additional file 3: Table E2. Genes (169) up regulated by $>1.5$ fold in both fibroblasts lines (L20 and L21) cultured with IL3lgG eosinophil conditioned media (average of 2 eosinophil donors), compared to HLF cultured in medium only, and cultured with rhlL-3 plus HA-lgG. (PDF $88 \mathrm{~kb}$ )

Additional file 4: Table E3. Genes (131) down regulated by $>1.5$ fold in both fibroblasts lines (L20 and L21) cultured with IL3lgG eosinophil conditioned media (average of 2 eosinophil donors), compared to HLF cultured in medium only, and cultured with rhlL-3 plus HA-lgG. (PDF 88 kb)

Additional file 5: Table E4. Upstream Regulators of the genes listed in our dataset (target genes, Additional file 3: Table E2 and Additional file 4: Table E3) as predicted by IPA analysis. (PDF $141 \mathrm{~kb}$ )

Additional file 6: Table E6. Genes downregulated by IL3lgG- versus IL5lgG-activated eosinophil conditioned medium and control media (medium only and rhlL3lgG) in fibroblasts. (PDF $94 \mathrm{~kb}$ )

Additional file 7: Table E5. HLF (L20 and L21) expression levels for the receptors of the upstream regulators identified by IPA (Tables 2 and 3, and Additional file 4: Table E3), as determined by our RNA-seq analysis. (PDF $92 \mathrm{~kb}$ )

Additional file 8: Figure E2. Global Molecular Network \#1 generated by IPA downstream analysis. Interactions between the genes of our dataset \#1 (300 genes) in relation with other neighboring genes present in a Global Molecular Network. Thirty-five total genes or group of genes are present in each network. This network characterized genes related to the inflammatory response and development disorder. It includes 15 genes and 1 group from our dataset. (PDF $321 \mathrm{~kb}$ )
Additional file 9: Figure E3. Global Molecular Network \#2 generated by IPA downstream analysis. Interactions between the genes of our dataset \#1 (300 genes) in relation with other neighboring genes present in a Global Molecular Network. Thirty-five total genes or group of genes are present in each network. This network characterized genes related to cellular movement, hematological system development and function and immune cell trafficking. It includes 15 genes and 4 groups from our dataset. (PDF $332 \mathrm{~kb}$ )

Additional file 10: Table E7. Association of the dataset \#2 genes with Global Molecular Networks created by IPA using dataset 1

(Figs. E1 and E2, and not shown). (PDF 86 kb)

\section{Abbreviations}

ECM: Extracellular matrix; EDN: Eosinophil-derived neurotoxin; FBS: Fetal bovine serum; GUSB: B-glucuronidase; HA-lgG: Heat aggregated lgG; HLF: Primary human lung fibroblasts; IgG: Immunoglobin-G; IL-1: Interleukin-1; IL3lgG: IL-3 primed for $20 \mathrm{~h}$ and seeded on HA-IgG for 6 h; IPA: Ingenuity pathway analysis; rhlL3lgG: Recombinant human IL-3 plus soluble heat aggregated IgG; RNAseq: RNA sequencing; TGF- $\beta$ : Transforming growth factor- $\beta$

\section{Acknowledgements}

The authors wish to thank Paul Fichtinger, BS of the Eosinophil Core facility (P.I., Sameer Mathur, M.D., Ph.D.) for blood eosinophil purification, the research nurse coordinators in the Clinical Core facility (P.I., Loren L. Denlinger, M.D., Ph.D.) for subject recruitment and screening. We thank Andrea Noll for laboratory technical support. We thank the University of Wisconsin (UW) Carbone Cancer Center (Madison, WI) for use of its Shared Services to complete this research.

\section{Funding}

NIH HL088594, UL1TR000427 and 5K08HL093367; ATS Foundation; Coalition for Pulmonary Fibrosis, and Pulmonary Fibrosis Foundation Research Grant; University of Wisconsin Comprehensive Cancer Center P30 CA014520; and the University of Wisconsin Development Funding.

\section{Availability of data and materials}

The data of the RNA sequencing will be deposited to NCBI Gene Expression Omnibus (GEO) database and assigned an accession number. The accession number will be provided in the manuscript.

\section{Authors' contributions}

SE participated in the design and coordination of the study; carried out eosinophil cultures, the RNA isolation, the PCR and the pathway analysis; and drafted the manuscript. KB participated in the fibroblast cultures and the $\mathrm{PCR}$; and helped to draft the manuscript. EET carried out the fibroblasts cultures and participated in the design of the study. YAB carried out the analysis of the RNA sequencing. NNJ and NS conceived the study, and participated in its design and coordination; and helped to draft the manuscript. All authors read and approved the final manuscript.

\section{Ethics approval and consent to participate}

The study protocol was approved by the University of Wisconsin-Madison Health Sciences Institutional Review Board (IRB). The use of blood eosinophils was approved by the IRB committee's reference number: 2014-1481. The use of pulmonary fibroblasts was approved by IRB committee's number: 2012-0061.

\section{Consent for publication}

Not applicable

\section{Competing interests}

Dr. Nizar Jarjour is a consultant for Astra Zeneca in the areas of developing new therapeutic for asthma and COPD. The other authors declare that they have no competing interests related to this work.

\section{Publisher's Note}

Springer Nature remains neutral with regard to jurisdictional claims in published maps and institutional affiliations. 


\section{Author details}

'Department of Medicine, Division of Allergy, Pulmonary and Critical Care Medicine, The University of Wisconsin-Madison School of Medicine and Public Health, K4/928 Clinical Science Center MC 9988, 600 Highland Avenue, Madison, WI 53792, USA. ${ }^{2}$ Department of Pediatrics, University of Wisconsin School of Medicine and Public Health, Madison, WI 53792, USA.

Received: 28 June 2017 Accepted: 30 October 2017

\section{Published online: 10 November 2017}

\section{References}

1. Bousquet J, Chanez P, Lacoste JY, Barneon G, Ghavanian N, Enander I, Venge P, Ahlstedt S, Simony-Lafontaine J, Godard P, et al. Eosinophilic inflammation in asthma. N Engl J Med. 1990;323:1033-9.

2. Malinovschi A, Fonseca JA, Jacinto T, Alving K, Janson C. Exhaled nitric oxide levels and blood eosinophil counts independently associate with wheeze and asthma events in National Health and nutrition examination survey subjects. J Allergy Clin Immunol. 2013;132:821-7. e821-825

3. Bel EH, Ortega HG, Pavord ID: Glucocorticoids and mepolizumab in eosinophilic asthma REPLY. N Engl J Med 2014, 371:2434-2434.

4. Ortega HG, Liu MC, Pavord ID, Brusselle GG, FitzGerald JM, Chetta A, Humbert M, Katz LE, Keene ON, Yancey SW, et al. Mepolizumab treatment in patients with severe eosinophilic asthma. N Engl J Med. 2014;371:1198-207.

5. Acharya KR, Ackerman SJ. Eosinophil granule proteins: form and function. J Biol Chem. 2014;289:17406-15.

6. Spencer LA, Bonjour K, Melo RC, Weller PF. Eosinophil secretion of granule-derived cytokines. Front Immunol. 2014;5:496.

7. Hahn AD, Cadman RV, Sorkness RL, Jarjour NN, Nagle SK, Fain SB. Redistribution of inhaled hyperpolarized $3 \mathrm{He}$ gas during breath-hold differs by asthma severity. J Appl Physiol (1985). 2016;120:526-36.

8. Al-Muhsen S, Johnson JR, Hamid Q. Remodeling in asthma. J Allergy Clin Immunol. 2011;128:451-62. quiz 463-454

9. Shen ZJ, Esnault S, Rosenthal LA, Szakaly RJ, Sorkness RL, Westmark PR Sandor M, Malter JS. Pin1 regulates TGF-beta1 production by activated human and murine eosinophils and contributes to allergic lung fibrosis. J Clin Invest. 2008;1 18:479-90.

10. Minshall EM, Leung DY, Martin RJ, Song YL, Cameron L, Ernst P, Hamid Q. Eosinophil-associated TGF-beta1 mRNA expression and airways fibrosis in bronchial asthma. Am J Respir Cell Mol Biol. 1997;17:326-33.

11. Jung Y, Wen T, Mingler MK, Caldwell JM, Wang YH, Chaplin DD, Lee EH, Jang MH, Woo SY, Seoh JY, et al. IL-1 beta in eosinophil-mediated small intestinal homeostasis and IgA production. Mucosal Immunol. 2015;8:930-42.

12. Burnham ME, Esnault S, Roti Roti EC, Bates ME, Bertics PJ, Denlinger LC. Cholesterol selectively regulates IL-5 induced mitogen activated protein kinase signaling in human eosinophils. PLoS One. 2014;9:e103122.

13. Esnault S, Kelly EA, Nettenstrom LM, Cook EB, Seroogy CM, Jarjour NN Human eosinophils release IL-1 $\beta$ and increase expression of IL-17A in activated CD4(+) T lymphocytes. Clin Exp Allergy. 2012;42:1756-64.

14. Wong CK, Cheung PF, Ip WK, Lam CW. Intracellular signaling mechanisms regulating toll-like receptor-mediated activation of eosinophils. Am J Respir Cell Mol Biol. 2007;37:85-96.

15. Kobayashi T, Kouzaki H, Kita H. Human eosinophils recognize endogenous danger signal crystalline uric acid and produce proinflammatory cytokines mediated by autocrine ATP. J Immunol. 2010;184:6350-8.

16. Verrecchia F, Chu ML, Mauviel A. Identification of novel TGF-beta /Smad gene targets in dermal fibroblasts using a combined cDNA microarray/ promoter transactivation approach. J Biol Chem. 2001;276:17058-62.

17. Batra V, Musani Al, Hastie AT, Khurana S, Carpenter KA, Zangrilli JG, Peters SP. Bronchoalveolar lavage fluid concentrations of transforming growth factor (TGF)-beta1, TGF-beta2, interleukin (IL)-4 and IL-13 after segmental allergen challenge and their effects on alpha-smooth muscle actin and collagen III synthesis by primary human lung fibroblasts. Clin Exp Allergy. 2004;34:437-44.

18. Lappalainen U, Whitsett JA, Wert SE, Tichelaar JW, Bry K. Interleukin-1 beta causes pulmonary inflammation, emphysema, and airway remodeling in the adult murine lung. Am J Respir Cell Mol Biol. 2005;32:311-8.

19. Heino J, Heinonen T. Interleukin-1 beta prevents the stimulatory effect of transforming growth factor-beta on collagen gene expression in human skin fibroblasts. Biochem J. 1990;271:827-30.

20. Saxena A, Chen W, Su Y, Rai V, Uche OU, Li N, Frangogiannis NG. IL-1 induces proinflammatory leukocyte infiltration and regulates fibroblast phenotype in the infarcted myocardium. J Immunol. 2013;191:4838-48.
21. Mia MM, Boersema M, Bank RA. Interleukin-1 beta attenuates myofibroblast formation and extracellular matrix production in dermal and lung fibroblasts exposed to transforming growth factor-beta1. PLoS One. 2014;9:e91559.

22. Rochester CL, Ackerman SJ, Zheng T, Elias JA. Eosinophil-fibroblast interactions. Granule major basic protein interacts with IL-1 and transforming growth factor-beta in the stimulation of lung fibroblast IL-6-type cytokine production. J Immunol. 1996;156:4449-56.

23. Gomes I, Mathur SK, Espenshade BM, Mori Y, Varga J, Ackerman SJ. Eosinophil-fibroblast interactions induce fibroblast IL-6 secretion and extracellular matrix gene expression: implications in fibrogenesis. J Allergy Clin Immunol. 2005;116:796-804.

24. Wong CK, Leung KM, Qiu HN, Chow JY, Choi AO, Lam CW. Activation of eosinophils interacting with dermal fibroblasts by pruritogenic cytokine IL-31 and alarmin IL-33: implications in atopic dermatitis. PLoS One. 2012;7:e29815.

25. Peebles RS Jr, Liu MC, Lichtenstein LM, Hamilton RG. IgA, IgG and IgM quantification in bronchoalveolar lavage fluids from allergic rhinitics, allergic asthmatics, and normal subjects by monoclonal antibody-based immunoenzymetric assays. J Immunol Methods. 1995;179:77-86.

26. Nahm DH, Kim HY, Park HS. Elevation of specific immunoglobulin a antibodies to both allergen and bacterial antigen in induced sputum from asthmatics. Eur Respir J. 1998;12:540-5.

27. Kaneko M, Horie S, Kato M, Gleich GJ, Kita H. A crucial role for beta 2 integrin in the activation of eosinophils stimulated by lgG. J Immunol. 1995: 155:2631-41.

28. Kaneko M, Swanson MC, Gleich GJ, Kita H. Allergen-specific IgG1 and IgG3 through Fc gamma RIl induce eosinophil degranulation. J Clin Invest. 1995; 95:2813-21.

29. Esnault S, Johansson MW, Kelly EA, Koenderman L, Mosher DF, Jarjour NN IL-3 up-regulates and activates human eosinophil CD32 and alphaMbeta2 integrin causing degranulation. Clin Exp Allergy. 2017;47:488-98.

30. Esnault S, Torr EE, Bernau K, Johansson MW, Kelly EA, Sandbo N, Jarjour NN. Endogenous semaphorin-7A impedes human lung fibroblast differentiation. PLoS One. 2017;12:e0170207.

31. Sandbo N, Ngam C, Torr E, Kregel S, Kach J, Dulin N. Control of myofibroblast differentiation by microtubule dynamics through a regulated localization of mDia2. J Biol Chem. 2013;288:15466-73.

32. Huang $\mathrm{d}$ W, Sherman BT, Lempicki RA. Systematic and integrative analysis of large gene lists using DAVID bioinformatics resources. Nat Protoc. 2009;4:44-57.

33. Zangari J, llie M, Rouaud F, Signetti L, Ohanna M, Didier R, Romeo B, Goldoni D, Nottet N, Staedel C, et al. Rapid decay of engulfed extracellular miRNA by XRN1 exonuclease promotes transient epithelial-mesenchymal transition. Nucleic Acids Res. 2017:45:4131-41.

34. Esnault S, Kelly EA, Schwantes EA, Liu LY, Delain LP, Hauer JA, Bochkov YA, Denlinger LC, Malter JS, Mathur SK, Jarjour NN. Identification of genes expressed by human airway eosinophils after an in vivo allergen challenge. PLoS One. 2013;8:e67560.

35. Melo RC, Weller PF. Piecemeal degranulation in human eosinophils: a distinct secretion mechanism underlying inflammatory responses. Histol Histopathol. 2010;25:1341-54.

36. Shen ZJ, Hu J, Esnault S, Dozmorov I, Malter JS. RNA Seq profiling reveals a novel expression pattern of TGF-beta target genes in human blood eosinophils. Immunol Lett. 2015;167:1-10.

37. Sawant KV, Xu R, Cox R, Hawkins H, Sbrana E, Kolli D, Garofalo RP, Rajarathnam K. Chemokine CXCL1-mediated Neutrophil trafficking in the lung: role of CXCR2 activation. J Innate Immun. 2015;7:647-58,

38. Kaur M, Singh D. Neutrophil chemotaxis caused by chronic obstructive pulmonary disease alveolar macrophages: the role of CXCL8 and the receptors CXCR1/CXCR2. J Pharmacol Exp Ther. 2013;347:173-80.

39. El Kebir D, Filep JG: Modulation of neutrophil apoptosis and the resolution of inflammation through beta2 integrins. Front Immunol 2013, 4:60.

40. Lyck R, Enzmann G. The physiological roles of ICAM-1 and ICAM-2 in neutrophil migration into tissues. Curr Opin Hematol. 2015;22:53-9.

41. Fielding CA, McLoughlin RM, McLeod L, Colmont CS, Najdovska M, Grail D, Ernst M, Jones SA, Topley N, Jenkins BJ. IL-6 regulates neutrophil trafficking during acute inflammation via STAT3. J Immunol. 2008;181:2189-95.

42. Coulthard LG, Woodruff TM. Is the complement activation product C3a a proinflammatory molecule? Re-evaluating the evidence and the myth. J Immunol. 2015;194:3542-8.

43. Yang S, Nakamura T, Hua Y, Keep RF, Younger JG, He Y, Hoff JT, Xi G. The role of complement C3 in intracerebral hemorrhage-induced brain injury. J Cereb Blood Flow Metab. 2006;26:1490-5. 
44. Wu F, Zou Q, Ding X, Shi D, Zhu X, Hu W, Liu L, Zhou H. Complement component C3a plays a critical role in endothelial activation and leukocyte recruitment into the brain. J Neuroinflammation. 2016;13:23.

45. Schraufstatter IU, Trieu K, Sikora L, Sriramarao P, DiScipio R. Complement C3a and C5a induce different signal transduction cascades in endothelial cells. J Immunol. 2002;169:2102-10.

46. Drouin SM, Kildsgaard J, Haviland J, Zabner J, Jia HP, PB MC Jr, Tack BF, Wetsel RA. Expression of the complement anaphylatoxin C3a and C5a receptors on bronchial epithelial and smooth muscle cells in models of sepsis and asthma. J Immunol. 2001;166:2025-32.

47. Cochrane CG, Muller-Eberhard HJ. The derivation of two distinct anaphylatoxin activities from the third and fifth components of human complement. J Exp Med. 1968;127:371-86.

48. Woolhiser MR, Brockow K, Metcalfe DD. Activation of human mast cells by aggregated IgG through FcgammaRl: additive effects of C3a. Clin Immunol. 2004;110:172-80

49. Asgari E, Le Friec G, Yamamoto H, Perucha E, Sacks SS, Kohl J, Cook HT, Kemper C. C3a modulates IL-1 beta secretion in human monocytes by regulating ATP efflux and subsequent NLRP3 inflammasome activation. Blood. 2013;122:3473-81

50. Hannedouche $S$, Zhang J, Yi T, Shen W, Nguyen D, Pereira JP, Guerini D, Baumgarten BU, Roggo S, Wen B, et al. Oxysterols direct immune cell migration via EBI2. Nature. 2011;475:524-7.

51. Shen ZJ, Hu J, Kashi VP, Kelly EA, Denlinger LC, Lutchman K, McDonald JG, Jarjour NN, Malter JS. Epstein-Barr virus induced gene 2 (EB|2) mediates allergen-induced, leukocyte migration into airways. Am J Respir Crit Care Med. 2017;195:1576-85.

52. Sugiura $H$, Koarai A, Ichikawa T, Minakata $Y$, Matsunaga $K$, Hirano $T$, Akamatsu K, Yanagisawa S, Furusawa M, Uno Y, et al. Increased 25hydroxycholesterol concentrations in the lungs of patients with chronic obstructive pulmonary disease. Respirology. 2012;17:533-40.

53. Ichikawa T, Sugiura H, Koarai A, Kikuchi T, Hiramatsu M, Kawabata H, Akamatsu K, Hirano T, Nakanishi M, Matsunaga K, et al. 25hydroxycholesterol promotes fibroblast-mediated tissue remodeling through NF-kappaB dependent pathway. Exp Cell Res. 2013;319:1176-86.

54. Harkness LM, Ashton AW, Burgess JK. Asthma is not only an airway disease, but also a vascular disease. Pharmacol Ther. 2015:148:17-33.

55. Salvato G. Quantitative and morphological analysis of the vascular bed in bronchial biopsy specimens from asthmatic and non-asthmatic subjects. Thorax. 2001;56:902-6.

56. Takishima T, Hida W, Sasaki H, Suzuki S, Sasaki T. Direct-writing recorder of the dose-response curves of the airway to methacholine. Clinical application. Chest. 1981;80:600-6.

57. Priego T, Sanchez J, Pico C, Ahrens W, De Henauw S, Kourides Y, Lissner L, Molnar D, Moreno LA, Russo P, et al. TAS1R3 and UCN2 transcript levels in blood cells are associated with sugary and fatty food consumption in children. J Clin Endocrinol Metab. 2015;100:3556-64.

58. Bakshi VP, Newman SM, Smith-Roe S, Jochman KA, Kalin NH. Stimulation of lateral septum CRF2 receptors promotes anorexia and stress-like behaviors: functional homology to CRF1 receptors in basolateral amygdala. J Neurosci. 2007;27:10568-77.

59. Yakabi K, Noguchi M, Ohno S, Ro S, Onouchi T, Ochiai M, Takabayashi H, Takayama K, Harada Y, Sadakane C, Hattori T. Urocortin 1 reduces food intake and ghrelin secretion via CRF(2) receptors. Am J Physiol Endocrinol Metab. 2011;301:E72-82.

60. Xiong Y, Qu Z, Chen N, Gong H, Song M, Chen X, Du J, Xu C. The local corticotropin-releasing hormone receptor 2 signalling pathway partly mediates hypoxia-induced increases in lipolysis via the CAMP-protein kinase a signalling pathway in white adipose tissue. Mol Cell Endocrinol. 2014;392:106-14.

61. Esnault S, Kelly EA, Johansson MW, Liu LY, Han S-H, Akhtar M, Sandbo N, Mosher DF, Denlinger LC, Mathur SK, et al. Semaphorin 7A is expressed on airway eosinophils and upregulated by IL-5 family cytokines. Clin Immunol. 2014;150:90-100

62. Esnault S, Kelly EA, Shen ZJ, Johansson MW, Malter JS, Jarjour NN. IL-3 maintains activation of the p90S6K/RPS6 pathway and increases translation in human eosinophils. J Immunol. 2015;195:2529-39.

\section{Submit your next manuscript to BioMed Central and we will help you at every step:}

- We accept pre-submission inquiries

- Our selector tool helps you to find the most relevant journal

- We provide round the clock customer support

- Convenient online submission

- Thorough peer review

- Inclusion in PubMed and all major indexing services

- Maximum visibility for your research

Submit your manuscript at www.biomedcentral.com/submit
Biomed Central 